\title{
Correlations of the Acoustic Fields of Mudejar-Gothic Churches
}

\author{
Miguel Galindo, Sara Girón and Teófilo Zamarreño \\ Departamento de Física Aplicada II, Universidad de Sevilla, E. T. S. de Arquitectura \\ IUACC, Avda. Reina Mercedes 2, 41012-Sevilla, Spain \\ mgalindo@us.es,sgiron@us.es,teofilo@us.es
}

(Received 3 March 2008 and accepted 26 August 2008)

\begin{abstract}
This paper studies the statistical correlations between monaural acoustic parameters with themselves and with architectural parameters from an acoustical survey undertaken in 12 Mudejar-Gothic churches in Seville, southern Spain. Objective room-acoustic parameters have been measured using impulse response analysis through a maximum-length-sequence measurement system in each church. Measurements cover time parameters (reverberation time, early decay time); levels (sound strength); energy-based parameters (centre time, clarity for speech, clarity, definition, early lateral energy fraction); and speech intelligibility (rapid speech transmission index) and the analysis takes into account both spatially averaged values and individual positions. The aim of the study is to identify the main architectural factors that have relevant influence on the acoustic fields of the churches, and the minimum number of room acoustic parameters which are able to describe adequately this acoustic field, thus the possible excess of information is evaluated. Significant correlations have been found that, in the best cases, correspond to fits using pairs of independent variables instead of one single variable. The best option to describe the six subjective attributes of sound perception in these buildings consists of three acoustic parameters formed by two different pairs plus the early lateral energy fraction.
\end{abstract}

\section{INTRODUCTION}

Ever since the 1950s, a number of monaural and binaural acoustic parameters based on experiments has been established for the evaluation of room sound quality in order to know relevant details of the sound field that were not previously covered, apart from the reverberation time (Sabine 1923). This has given rise to a multivariable and multipositional study of a closed enclosure. The singular development of electronics and computer science has propitiated a great advance in building acoustics measurements (ISO 18233 [1]). In addition, these objective acoustic parameters are well correlated to the subjective judgments of music, speech and singing, giving rise to the consensus expressed in ISO-3382 [2] (currently under revision ISO/DIS 3382-1 [3]). 
From the very beginning, research has been aimed at identifying dependencies of acoustic parameters on geometric dimensions in order to enable spaces to be designed with appropriate variables for sound quality, as the general tendency to investigate the relationships between acoustics and architecture bears witness. At the same time, correlations between different acoustic parameters have also been studied in order to determine the number of strictly independent variables of the existing group.

Hence in a precursor study in concert halls, Schroeder et al [4] studied the dependence of some acoustic parameters on hall volume and width. Later Gade [5,6], in a report concerning 11 European concert halls, showed the necessity of using at least one objective parameter per subjective aspect (reverberance/clarity, level and spaciousness) and employed statistical methods to determine the mutual connections between the room-acoustic parameters and their dependence on architectural design variables. A similar analysis was carried out by Pelorson et al [7] in 14 concert halls, and, more recently the study of Hidaka et al [8] correlated objective acoustical factors and architectural parameters in 18 European and Japanese chamber-music halls to reveal four orthogonal objective acoustic parameters (reverberation time, strength, initial time delay gap and binaural quality index) in their sound fields.

In the specific area of worship buildings, Carvalho [9] published the statistical relationships between 6 objective acoustic parameters using averaged and total data in 41 Catholic churches of different styles in Portugal. Through linear and non-linear regression, this same author [10] later studied the relationships between 8 objective acoustical measures (lateral fraction was excluded) using averaged data with 13 architectural features of the churches. Higher correlations were found in the non-linear case in both papers and it was also concluded that the most significant parameters to describe the acoustics of a church were the reverberation time, the clarity and the total sound level. The Portuguese report took into account other aspects such as an in-depth study of the speech intelligibility of the churches through RASTI measures and its relationships with architectural features [11,12], and the relationships of the subjective parameters with the objective measures and with architectural features [13]. Furthermore, Magrini et al [14] made a contribution along these lines by studying 10 churches in Italy of different styles and the correlation [15] between several room acoustic parameters and the church volume and volume/floor surface ratio. To conclude this review, it should be mentioned that Cirillo et al [16] studied the acoustic properties of a special typology of church in Italy, the Apulian-Romanesque. They found remarkable relationships [17] between reverberation times at mid-frequencies and geometric parameters only when similar mean absorption coefficients were involved; all the other room acoustic parameters presented poor correlations with architectural parameters. As for the correlations between acoustic parameters themselves, they highlighted an excess of information in the same way as did Carvalho, and proposed the early decay time, the sound strength and the interaural cross-correlation coefficient as the three acoustic parameters that characterize the acoustic field of this type of church.

In this paper the experimental data obtained in the Mudejar-Gothic churches [18]; and which have been analysed from different points of view such as the distribution of omnidirectional acoustic energy [19], the distribution of speech intelligibility 

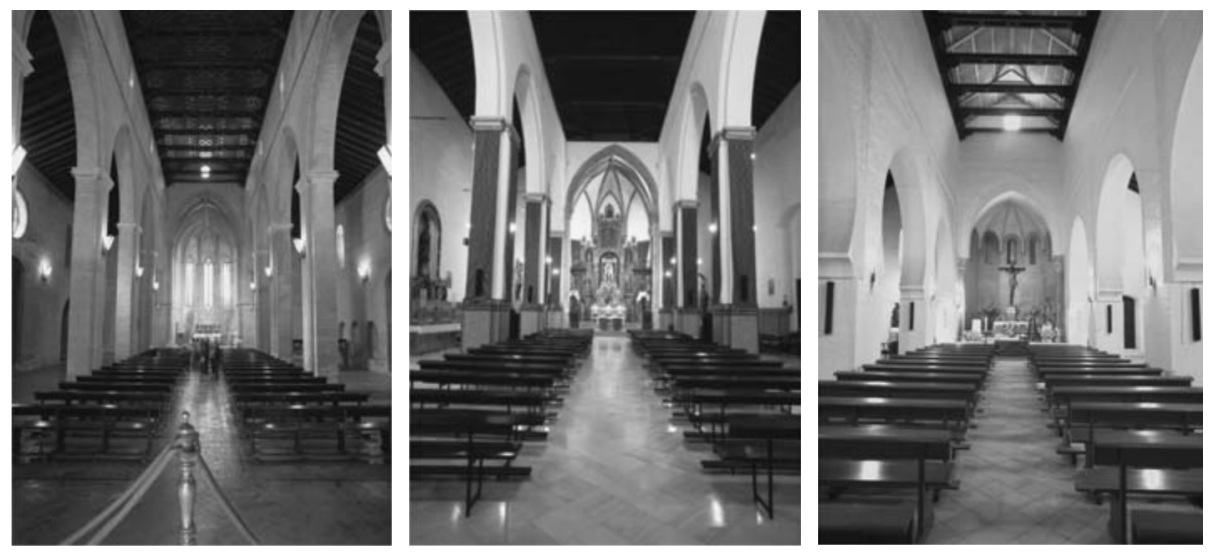

Figure 1. (a) Interior of Santa Marina church (left), San Julián church (centre) and San Marcos church (right).

descriptors [20], and the directional energy parameter [21], have been collected together in order to examine the statistical correlations between acoustic and architectural parameters and between acoustic parameters themselves.

\section{MUDEJAR-GOTHIC CHURCHES}

All these churches were built in the Middle Ages and have suffered restorations and adaptations throughout their existence due to several reasons (including earthquakes, fires, and deterioration). Their architectural style was the result of a unique Spanish artistic movement since it was influenced by both Islamic and Gothic Christian elements.

The Mudejar-Gothic churches in Seville, all located in its historical centre, are morphologically characterized by this stylistic dualism: a vaulted Gothic apse and a body of three naves with a timber roof (collar beam in the main nave) of Moorish origin. Their brick walls are complemented with portals and a stone apse. The supports are also clearly Islamic, with quadrangular or sometimes octagonal pillars and with raised brick mouldings as decoration. Pointed, round or segmental arches rest on these supports. In order to complete the description of these religious spaces, Fig. 1(a) shows some photographs taken in Santa Marina, San Julián and San Marcos churches.

Among other elements of particular interest, funeral chapels have been successively added to the side naves which, on some occasions, are housed in remaining sections of pre-existent mosques. Funeral chapels do not exist in San Julián, San Esteban and San Marcos churches.

Figure 1(b) shows the ground plan for each church studied in this paper, with the source and receiver positions for measurements and the seating areas. These drawings are all on the same scale and presented in order of decreasing volume. The name of each church is accompanied by its abbreviation which is used in the tables throughout the paper. 

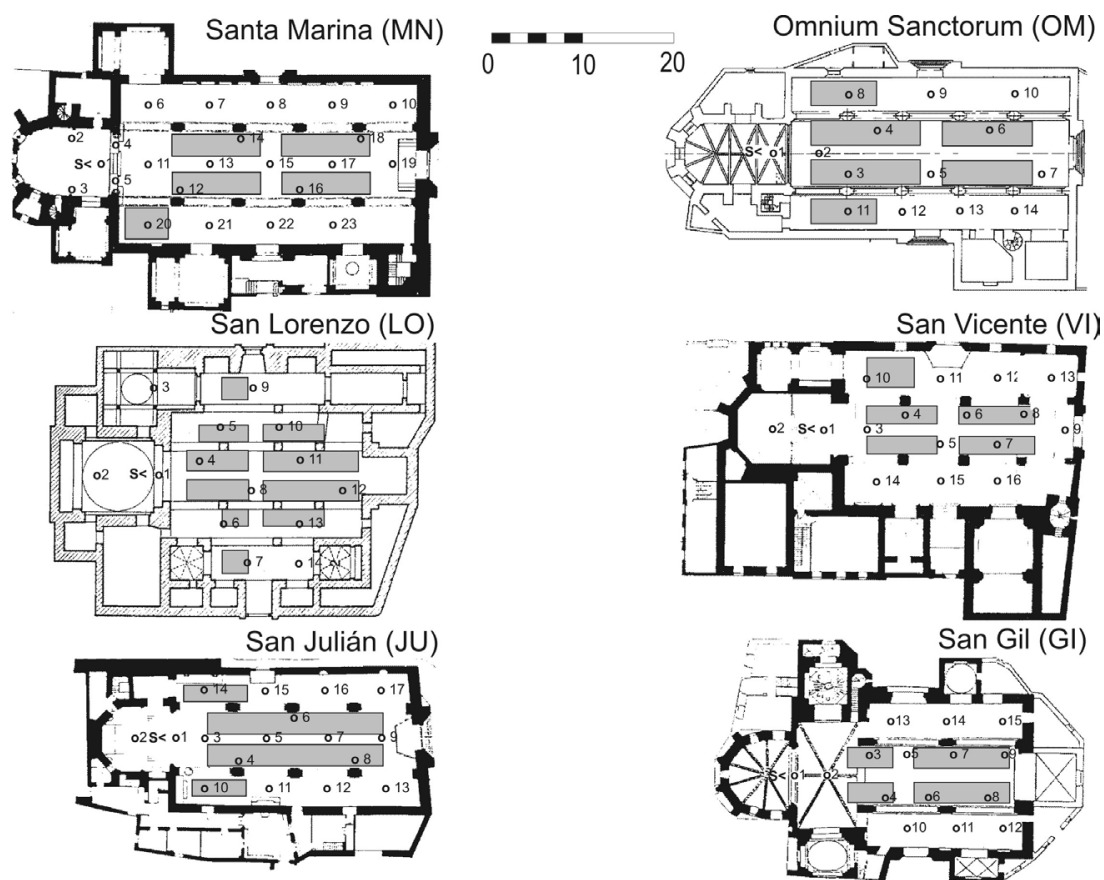

San Vicente (VI)

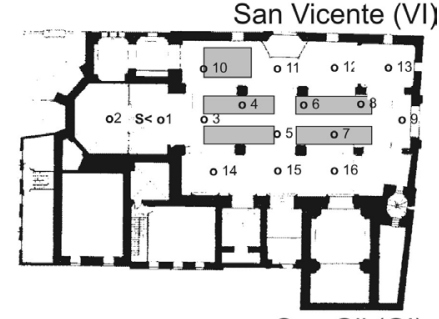

San Pedro (PE)
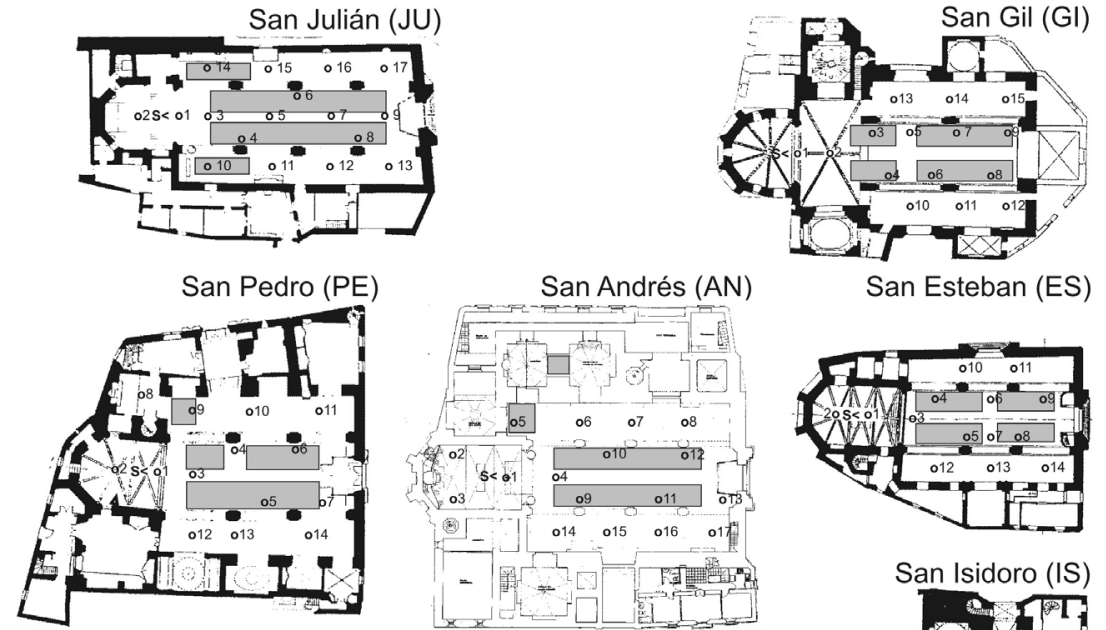

San Marcos (MC)
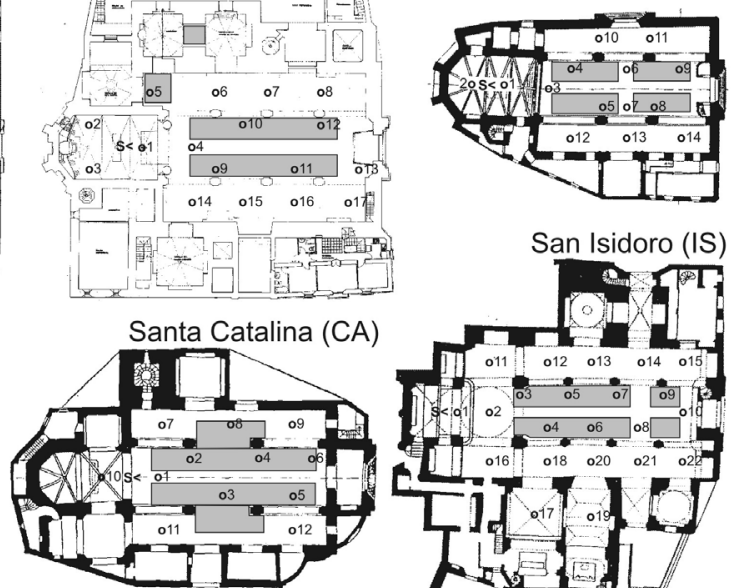

San Isidoro (IS)

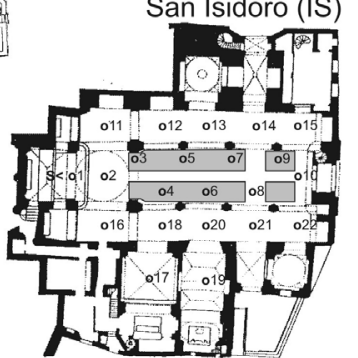

Figure 1. (b) Ground Plan with the source (S) and receiver positions (O) for measurements, pew zone (shaded area), for the 12 churches.

Table 1 summarizes some geometric and architectural data of interest, obtained through measurement or building plans, and a brief description of the interior finishes for the twelve churches: 
Table 1: Significant data of the churches

\begin{tabular}{|c|c|c|c|c|c|c|c|c|}
\hline Church & $\begin{array}{c}\mathbf{V} \\
\left(\mathbf{m}^{3}\right)\end{array}$ & $\begin{array}{c}\mathbf{L} \\
(\mathbf{m})\end{array}$ & $\begin{array}{c}\mathbf{W} \\
(\mathbf{m})\end{array}$ & $\begin{array}{c}\mathbf{H} \\
(\mathbf{m})\end{array}$ & $\begin{array}{c}\mathbf{S}_{\mathrm{T}} \\
\left(\mathbf{m}^{2}\right)\end{array}$ & $\begin{array}{c}\mathbf{S}_{\mathrm{C}+\mathbf{S}_{\mathrm{L}}} \\
(\mathbf{m})\end{array}$ & $\begin{array}{l}\mathbf{V} / \mathbf{S}_{\mathbf{G}} \\
\left(\mathbf{m}^{3 / 2}\right)\end{array}$ & Finish $(*)$ \\
\hline $\mathrm{MN}$ & 10708 & 34 & 19 & 15 & 4517 & $250+279$ & 20.24 & $(\mathrm{v}),(-),(\mathrm{s}),(\mathrm{w}), 3 \mathrm{si}$ \\
\hline $\mathrm{OM}$ & 8180 & 29 & 16 & 16 & 3760 & $194+219$ & 19.81 & $(\mathrm{pp}),(\mathrm{mc}),(\mathrm{p}),(\mathrm{w}), 2 \mathrm{do}$ \\
\hline LO & 7040 & 24 & 24 & 16 & 3346 & $132+267$ & 17.64 & $(\mathrm{pp}),(\mathrm{wc}),(\mathrm{p}),(\mathrm{w}), 2 \mathrm{do}$ \\
\hline VI & 6915 & 26 & 18 & 11 & 3656 & $144+180$ & 21.34 & $(\mathrm{pp}),(-),(\mathrm{f}),(\mathrm{w}), 2 \mathrm{do}, 1 \mathrm{si}$ \\
\hline JU & 6226 & 27 & 15 & 13 & 3321 & $187+150$ & 18.47 & $(\mathrm{pp}),(\mathrm{wc}),(\mathrm{f}),(\mathrm{w}), 1 \mathrm{do}$ \\
\hline GI & 6200 & 22 & 15 & 14 & 3249 & $170+148$ & 19.50 & (pp), (wc), (f), (w), 2do \\
\hline PE & 6180 & 20 & 17 & 16 & 3035 & $123+154$ & 22.05 & $(\mathrm{pp}),(\mathrm{wc}),(\mathrm{p}),(\mathrm{t}), 2 \mathrm{do}$ \\
\hline AN & 5955 & 23 & 15 & 11 & 3380 & $132+154$ & 20.82 & $(\mathrm{pp}),(-),(\mathrm{f}),(\mathrm{w}), 2 \mathrm{do}, 1 \mathrm{si}$ \\
\hline ES & 4746 & 20 & 14.5 & 14 & 2691 & $141+134$ & 17.26 & $(\mathrm{v}),(-),(\mathrm{p}),(\mathrm{w}), 1 \mathrm{do}, 1 \mathrm{si}$ \\
\hline $\mathrm{MC}$ & 4623 & 26 & 17 & 10 & 3041 & $144+226$ & 12.49 & $(\mathrm{~d}),(-),(\mathrm{s}),(\mathrm{r}), 2 \mathrm{si}$ \\
\hline CA & 4362 & 22 & 15 & 12 & 2474 & $121+102$ & 19.56 & $(\mathrm{pp}),(-),(\mathrm{p}),(\mathrm{w}), 2 \mathrm{do}$ \\
\hline IS & 3947 & 26 & 14.5 & 11 & 2547 & $133+144$ & 14.25 & $(\mathrm{pp}),(\mathrm{mc}),(\mathrm{f}),(\mathrm{w}), 1 \mathrm{si}$ \\
\hline
\end{tabular}

*Lateral wall: $\mathbf{v}=$ visible brick; $\mathbf{p p}=$ plastered and painted; $\mathbf{d}=$ directly painted brick.

Baseboard: $\mathbf{m c}=$ major chapel; $\mathbf{w c}=$ whole church.

Decoration: $\mathbf{s}=$ scarce; $\mathbf{f}=$ fair; $\mathbf{p}=$ profuse.

Ceiling: $\mathbf{w}=$ wooden framework in three naves; $\mathbf{t}=$ tiles substitute the wooden board in the laterals;

$\mathbf{r}=$ rough ceramics substitute the wooden boards in the central nave.

Inner doors: si=single; $\mathbf{d o}=$ double.

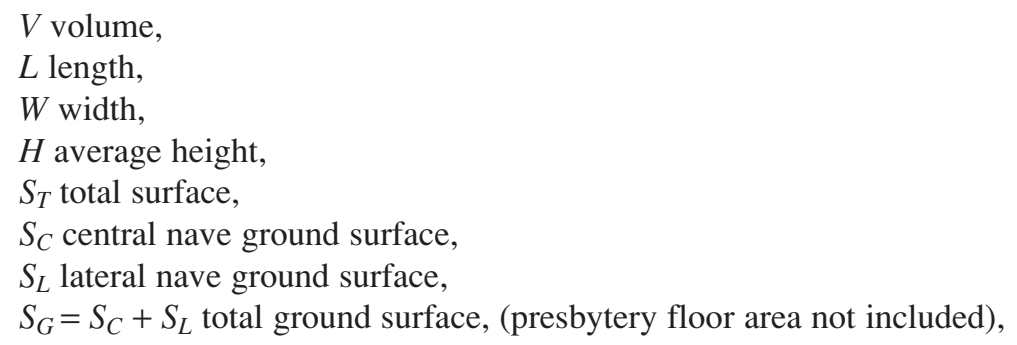

The church floors are of marble or ceramic material and the congregational seating area consists of wooden pews distributed in the main nave and also occasionally in the lateral naves (shaded area in Fig.1(b)). A complete description of the furnishings and other acoustical information on these temples can be found in Galindo et al [18].

\section{MEASUREMENT TECHNIQUES}

The procedures employed have been those established in ISO 18233 [1], ISO 3382 [2] and IEC 60268-16 [22] standards, and all measures were carried out in unoccupied churches. Temperature and relative humidity have been monitored during the measurements. The range of variation in all churches was $22.6-27.4{ }^{\circ} \mathrm{C}$ for the 
temperature, 35.7-65.7 \% for the relative humidity and 101.7-102.5 $\mathrm{kPa}$ for the atmospheric pressure.

Monaural impulse responses (IR) and other room responses to stationary signals have been measured to determine the following parameters for each frequency band between $125-4000 \mathrm{~Hz}$ in all receiver positions:

- reverberation time $(T)$

- early decay time $(E D T)$ for the evaluation of reverberation characteristics,

- sound strength $(G)$ to explore the sound level distribution within the measuring area,

- centre time $\left(T_{s}\right)$,

- clarity for speech $\left(C_{50}\right)$, clarity $\left(C_{80}\right)$ and definition $\left(D_{50}\right)$, as energy-based parameters related to the early-to-late or early-to-total sound energy ratio,

- $\quad$ early lateral energy fraction $(L F)$ to study the spatial impression phenomena in these places, and finally,

- the RASTI index to evaluate the intelligibility from the degradation of the modulation transfer function.

All these objective descriptors assess the perception of music, speech and singing in these religious places.

The IR has been obtained using MLS (Maximum Length Sequence) signals generated and analysed by the analyser MLSSA from DRA laboratories. The omnidirectional source (B\&K 4296) was placed at the most usual point of location of the natural source: the altar at a height of $1.70 \mathrm{~m}$ from the floor. The microphone (omnidirectional B\&K 4190 1/2-in or multipattern Audio-Technica AT4050/CM5) was located at the approximate height of the head of a seated person $\sim 1.20 \mathrm{~m}$, in a predetermined number of positions distributed in the central nave and the lateral naves, ranging from 12 reception points for Santa Catalina church to 23 for Santa Marina (Fig. 1(b)).

The calculation of sound strength uses the emission of a stationary signal, related the level produced by the source, at $10 \mathrm{~m}$ distance under free field conditions. The equivalence of these results with those obtained by MLS signals has been also published elsewhere [18]. The RASTI values used in this paper have been obtained using the B\&K 3361 system, which uses the modulated stationary noise technique. The equivalence of these results with those obtained through the MLS spectrum has also been proved in previous published work [18].

To characterize the acoustics of each church, the following multi-octaved band average indices have been calculated:

- clarity and centre time as a direct average of the values at frequencies of 500, 1000, and $2000 \mathrm{~Hz}$,

- clarity for speech and definition as a weighted average as Marshall [23] proposed:

$$
C_{50 a v}=0.15 C_{50}(500 H z)+0.25 C_{50}(1 k H z)+0.35 C_{50}(2 k H z)+0.25 C_{50}(4 k H z),
$$

- reverberation time, early decay time and sound strength as a mean of the corresponding values at mid-frequency 500 and $1000 \mathrm{~Hz}$ bands, and

- early lateral fraction as a direct average of 125, 250, 500, and $1000 \mathrm{~Hz}$ octave bands [3]. 
Table 2: Spatially averaged room-acoustic parameters in each church

\begin{tabular}{lccccccccc}
\hline Church & $\mathbf{T}(\mathbf{s})$ & $\mathbf{E D T}(\mathbf{s})$ & $\mathbf{T}_{\mathbf{S}}(\mathbf{m s})$ & $\mathbf{G}(\mathbf{d B})$ & $\mathbf{C}_{\mathbf{8 0}}(\mathbf{d B})$ & $\mathbf{C}_{\mathbf{5 0 a v}}(\mathbf{d B})$ & $\mathbf{D}_{\mathbf{5 0}}(\boldsymbol{\%})$ & $\mathbf{L F}(\boldsymbol{\%})$ & RASTI \\
\hline MN & 3.09 & 3.12 & 213 & 7.88 & -3.03 & -4.48 & 30.0 & 17 & 0.38 \\
OM & 2.74 & 2.85 & 208 & 7.89 & -3.36 & -5.51 & 25.3 & 17 & 0.40 \\
LO & 2.29 & 2.38 & 172 & 7.04 & -2.42 & -4.17 & 29.2 & 21 & 0.47 \\
VI & 2.48 & 2.49 & 190 & 8.30 & -2.87 & -5.14 & 26.2 & 14 & 0.42 \\
JU & 2.28 & 2.15 & 152 & 8.37 & -1.29 & -2.56 & 35.2 & 17 & 0.49 \\
GI & 2.28 & 2.33 & 167 & 7.48 & -2.14 & -3.70 & 31.3 & 18 & 0.45 \\
PE & 2.06 & 2.00 & 148 & 9.47 & -1.74 & -3.79 & 32.9 & 18 & 0.47 \\
AN & 2.00 & 1.97 & 151 & 9.22 & -2.32 & -5.48 & 29.7 & 23 & 0.45 \\
ES & 2.02 & 1.88 & 136 & 8.50 & -0.83 & -3.18 & 34.0 & 17 & 0.43 \\
MC & 3.25 & 3.59 & 269 & 11.5 & -5.77 & -8.21 & 16.3 & 16 & 0.35 \\
CA & 1.61 & 1.56 & 104 & 9.15 & 1.10 & -1.76 & 42.7 & 20 & 0.60 \\
IS & 2.22 & 2.41 & 189 & 9.33 & -4.05 & -6.54 & 20.0 & 20 & 0.42 \\
\hline
\end{tabular}

Table 3: Linear correlation between acoustic parameters and geometric parameters $R^{2}<0.25$ are excluded and those with $R^{2}>0.50$ in bold. Underlining means $\mathbf{P}<0.05$

\begin{tabular}{lccccccccc}
\hline Parameters & $\mathbf{W}$ & $\mathbf{L}$ & $\mathbf{H}$ & $\mathbf{H} / \mathbf{W}$ & $\mathbf{S}_{\mathbf{T}}$ & $\mathbf{S}_{\mathbf{G}}=\mathbf{S}_{\mathbf{C}}+\mathbf{S}_{\mathbf{L}}$ & $\mathbf{V}$ & $\mathbf{V} / \mathbf{S}_{\mathbf{G}}$ & $\mathbf{V} / \mathbf{S}_{\mathbf{T}}$ \\
\hline $\mathrm{T}$ & --- & $\underline{\mathbf{0 . 7 5}}$ & --- & --- & $\underline{\mathbf{0 . 7 6}}$ & $\underline{\mathbf{0 . 8 4}}$ & $\underline{\mathbf{0 . 7 6}}$ & --- & $\underline{\mathbf{0 . 5 2}}$ \\
EDT & --- & $\underline{0.48}$ & --- & --- & 0.28 & $\underline{\mathbf{0 . 5 6}}$ & --- & -- & --- \\
$\mathrm{T}_{\mathrm{S}}$ & --- & $\underline{0.39}$ & --- & --- & --- & 0.43 & --- & 0.27 & --- \\
$\mathrm{G}$ & --- & --- & 0.29 & --- & --- & --- & --- & --- & $\underline{0.33}$ \\
$\mathrm{C}_{80}$ & --- & --- & --- & --- & --- & --- & --- & $\underline{0.31}$ & --- \\
$\mathrm{C}_{50}$ & --- & --- & --- & 0.27 & --- & --- & --- & 0.29 & --- \\
$\mathrm{D}_{50}$ & --- & --- & --- & --- & --- & --- & --- & $\underline{0.35}$ & --- \\
LF & --- & --- & --- & --- & --- & --- & --- & -- & --- \\
RASTI & --- & --- & --- & --- & --- & 0.27 & --- & 0.28 & --- \\
\hline
\end{tabular}

\section{ANALYSIS OF THE POSITION-AVERAGED DATA}

This section deals with the results of analysing the set of data from the churches by linear and non-linear regression methods. The aims of the analyses are to reveal the dependencies of room acoustic parameters on architectural variables. Throughout this section, frequency (as described in section 3) and position-averaged values will be discussed since the design aspects are related to the overall features of the churches.

\subsection{Correlations with one geometric variable}

Table 2 summarizes the results of the 9 monaural acoustic parameters analysed in each church. These acoustic variables are shown in Table 3 linearly correlated with the 7 geometric variables specified in the heading of Table 1 plus the mean height/width, 
$\mathrm{H} / \mathrm{W}$, and volume/total surface, $\mathrm{V} / \mathrm{S}_{\mathrm{T}}$, ratios. Their most significant dependencies are represented by the inclusion of the coefficient of determination, $\mathrm{R}^{2}$. Correlations for which $\mathrm{R}^{2}<0.25$ are excluded and those for which $\mathrm{R}^{2}>0.5$ are written in bold.

The significant $P$ values have also been indicated by underlining their corresponding $\mathrm{R}^{2}$ value. It can usually be concluded that the independent variable can be used to predict the dependent variable when $P<0.05$. Only eleven correlations achieve this condition, giving $\mathrm{T}$ as the best estimated acoustic parameter.

These results show the following features:

- The best linear regression fits were found to be between the church floor surface area and reverberation time $\mathrm{T}$, and between the church floor surface area and early decay time EDT, whose results are expressed in eqns (2 - 3).

$$
\begin{gathered}
T=8.58 \cdot 10^{-1}+4.26 \cdot 10^{-3}\left(S_{C}+S_{L}\right) \\
E D T=6.69 \cdot 10^{-1}+5.13 \cdot 10^{-3}\left(S_{C}+S_{L}\right)
\end{gathered}
$$

- No parameter is correlated with the church width.

- The early lateral energy fraction LF has no significant dependence on the church architectural parameters.

- The omnidirectional energy-based acoustic parameters centre time $\mathrm{T}_{\mathrm{s}}$, clarity $\mathrm{C}_{80}$, clarity for speech $\mathrm{C}_{50}$, and definition $\mathrm{D}_{50}$ present some noticeable correlations with the ratio $\mathrm{V} / \mathrm{S}_{\mathrm{G}}$.

- In the same way, the sound strength $\mathrm{G}$ shows only a weak dependence on the height $\mathrm{H}$ and the $\mathrm{V} / \mathrm{S}_{\mathrm{T}}$ ratio. This is a logical result because the averaged values for these churches are approximately constant (see column $\mathrm{G}$ in Table 2) and hence $\mathrm{G}$ (frequency and spatially averaged) can be considered as a typological constant parameter. The standard deviation $(1.17 \mathrm{~dB})$ is approximately the JND for this parameter.

- Finally, speech intelligibility seems to be affected by the church floor surface area.

In Fig. 2, as an example of the whole set of results, the regression calculated between the RASTI index and the $\mathrm{V} / \mathrm{S}_{\mathrm{G}}$ ratio is shown. Although the correlation is poor it can be seen that most points are in the $95 \%$ confidence interval.

From all the linear tests carried out it is also possible to emphasize the following trends:

- Reverberation times increase with church length, total surface area and floor surface area.

- $\quad$ Early decay times increase with church length and floor surface area.

- Centre time increases with church floor surface area.

- Clarity, clarity for speech and definition decrease as the width of the churches increase.

Other dependencies are not clear. 


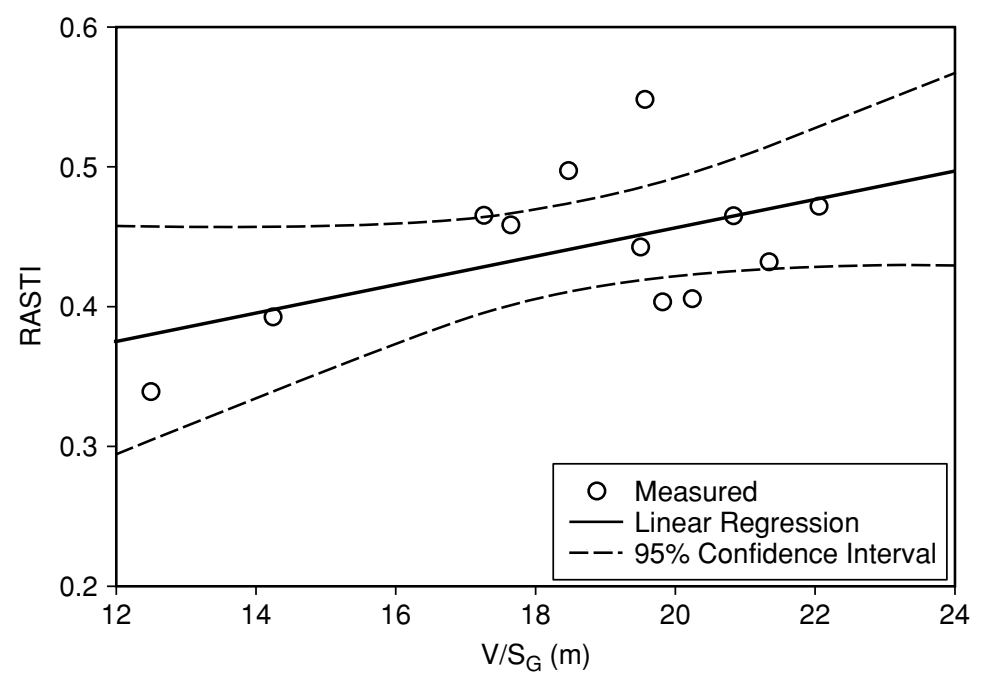

Figure 2. RASTI values as a function of the $\mathrm{V} / \mathrm{S}_{\mathrm{G}}$ ratio.

Table 4: Coefficients of determination $R^{2}>0.25,\left(R^{2}>0.50\right.$ in bold) in non-linear correlations; almost all are third-order functions: cubic $(+)$ or inverse, with two exceptions $l n$ and $\exp$, respectively. An underlined value means $\mathbf{P}<0.05$

\begin{tabular}{|c|c|c|c|c|c|c|c|c|c|}
\hline Parameters & $\mathbf{W}$ & $\mathbf{L}$ & $\mathbf{H}$ & $\mathbf{H} / \mathbf{W}$ & $\mathbf{S}_{\mathbf{T}}$ & $\mathbf{S}_{\mathrm{G}}=\mathbf{S}_{\mathrm{C}}+\mathbf{S}_{\mathrm{L}}$ & $\mathbf{V}$ & $\mathrm{V} / \mathrm{S}_{\mathrm{G}}$ & $\mathbf{V} / \mathbf{S}_{\mathbf{T}}$ \\
\hline $\mathrm{T}$ & $0.47_{+}$ & $\underline{0.79}$ & $\underline{\mathbf{0 . 6 0}}_{+}$ & --- & 0.79 & $\underline{0.88}_{+}$ & $\underline{0.94}$ & --- & $\underline{0.69}$ \\
\hline EDT & 037 & 0.51 & $\underline{0.69}+$ & 0.38 & 0.35 & $\underline{0.63}$ & --- & $0.51_{+}$ & $\underline{0.74}$ \\
\hline $\mathrm{T}_{\mathrm{S}}$ & 0.29 & 0.46 & $\overline{\underline{0.73}}_{+}$ & 0.44 & --- & $\overline{\mathbf{0 . 5 4}}_{+}$ & --- & $0.57_{+}$ & 0.71 \\
\hline G & --- & --- & 0.52 & 0.51 & $0.32_{1 \mathrm{n}}$ & $\overline{---}$ & $\underline{0.59}$ & 0.54 & $\overline{0.38+}$ \\
\hline $\mathrm{C}_{80}$ & --- & 0.38 & $\underline{0.67}+$ & $0.44_{+}$ & --- & 0.44 & $\overline{---}$ & $\mathbf{0 . 5 2} 2_{+}$ & $\underline{0.69}$ \\
\hline $\mathrm{C}_{50}$ & --- & 0.30 & $\underline{0.74}+$ & $0.49_{+}$ & --- & 0.27 & --- & $\mathbf{0 . 5 6}_{+}$ & $\underline{\mathbf{0 . 6 0}}_{+}$ \\
\hline $\mathrm{D}_{50}$ & --- & 0.33 & $\underline{0.66}_{+}$ & $0.49_{+}$ & --- & --- & --- & $0.566_{+}$ & $\underline{0.68}$ \\
\hline $\mathrm{LF}$ & 0.32 & --- & --- & $0.45_{+}$ & 0.29 & $0.41_{+}$ & --- & --- & --- \\
\hline RASTI & --- & 0.33 & $\underline{0.68}_{+}$ & $0.35_{+}$ & --- & $0.45_{\exp }$ & --- & $\mathbf{0 . 5 0 _ { + }}$ & $\underline{0.71}$ \\
\hline
\end{tabular}

When non-linear correlations are calculated, the number of significant correlations increases notably and the coefficients of determination improve in relation to those obtained in the linear relationships. Table 4 summarizes the results obtained where in all cases the best results correspond to third-order functions (cubic $\left(_{+}\right)$in Table 4, or inverse, unmarked). There are two exceptions: a third-order logarithm type, $y=y_{0}$ $+a \ln x+b(\ln x)^{2}+c(\ln x)^{2},((\ln )$, in Table 4); and an exponential decay, $y=a \exp (b /$ $(x+c))$, ((exp), in Table 4). Again the significant $P$ values have been indicated by underlining their corresponding $\mathrm{R}^{2}$ value. There is an increase in the number of correct estimations in relation to linear estimations, where $\mathrm{T}$ is again the best estimated 
acoustic parameter. In addition, the best architectural parameters for the estimations are $\mathrm{H}$ and $\mathrm{V} / \mathrm{S}_{\mathrm{T}}$.

The main features can be outlined as follows:

- $\quad$ The best fits with the architectural parameters are again in the reverberation time and early decay time parameters.

- Although dependence on church width improves in this case, it is not a determinant factor, since the best variables are the height and the $\mathrm{V} / \mathrm{S}_{\mathrm{T}}$ ratio.

- Early lateral acoustic energy values are not predicted with accuracy in any of the tested correlations (linear and non-linear), where the best option is the relationship with the $\mathrm{H} / \mathrm{W}$ church ratio.

By omitting the early lateral energy fraction, the following eqns $(4-11)$ show the dependence of each acoustic parameter on that geometric parameter which is the best fit:

$$
\begin{gathered}
T=1.5 \cdot 10^{-1}+7.9 \cdot 10^{4} V^{-1}-6.5 \cdot 10^{8} V^{-2}+1.5 \cdot 10^{12} V^{-3} \\
E D T=-53.4+365.3\left(V / S_{T}\right)^{-1}-771.4\left(V / S_{T}\right)^{-2}+527.3\left(V / S_{T}\right)^{-3} \\
T_{S}=12436.6-2752.4 H+203.3 H^{2}-4.9 H^{3} \\
G=3.1 \cdot 10^{1}-4.5 \cdot 10^{5} V^{-1}+3.0 \cdot 10^{9} V^{-2}-6.0 \cdot 10^{12} V^{-3} \\
C_{80}=232.4-1454.9\left(V / S_{T}\right)^{-1}+2955.9\left(V / S_{T}\right)^{-2}-1967.4\left(V / S_{T}\right)^{-3} \\
C_{50}=-295.1+62.1 H-4.4 H^{2}+0.1 H^{3} \\
D_{50}=1.1 \cdot 10^{3}-6.7 \cdot 10^{3}\left(V / S_{T}\right)^{-1}+1.3 \cdot 10^{4}\left(V / S_{T}\right)^{-2}-8.8 \cdot 10^{3}\left(V / S_{T}\right)^{-3} \\
R A S T I=6.3-37.2\left(V / S_{T}\right)^{-1}+77.1\left(V / S_{T}\right)^{-2}-52.2\left(V / S_{T}\right)^{-3}
\end{gathered}
$$

As in the linear case, the best results are obtained with relationships that involve the extinction of the signal, the reverberation time or the early decay time, especially the reverberation time. In this way, eqn (4) is the one with the best coefficient of determination and which best highlights the dependence of reverberation time on volume. This fact together with the correlation with the $\mathrm{V} / \mathrm{S}_{\mathrm{T}}$ ratio make it straightforward to calculate reverberation time.

According to the results, in these churches the acoustic behaviour seems to be connected to the geometric ratio $\mathrm{V} / \mathrm{S}_{\mathrm{T}}$ and to their $\mathrm{H}$, which are the two geometric parameters to which acoustic parameters correlate with the highest coefficient of determination. However, no geometric parameter is correlated with the early lateral acoustic energy. Due to the fact that the correlations are higher, the geometric factor to be considered as providing the first approximation of the trends of the room acoustic 


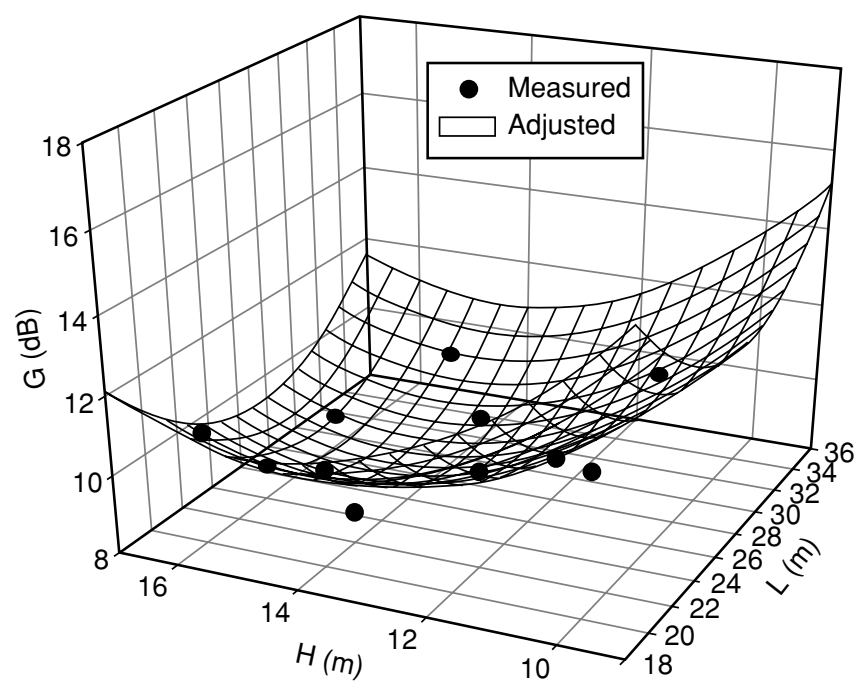

Figure 3. 3D plotted graph of $\mathrm{G}$ as a function of $\mathrm{H}$ and $\mathrm{L}$ geometric parameters.

parameters would be the $\mathrm{V} / \mathrm{S}_{\mathrm{T}}$ church ratio, except for the early lateral acoustic energy. This rough estimation could be due to the fact that all the churches are of the same typology with constant shape and sometimes similar dimensions.

\subsection{Statistical correlations with two geometric variables}

The next logical step is to seek correlations between the room-average acoustic parameters and two geometrical variables in an effort to find more reliable fits and to compensate for the deficit generated by the early lateral fraction and/or to diminish the number of geometric parameters to be used as variables. To this end, possible correlations between room acoustic parameters and two architectural dimensions have been studied. This has given rise to a number of $3 \mathrm{D}$ plots.

As an example, Fig. 3 shows one of the fits obtained which relates to the sound strength as a function of length and mean height of the churches. It corresponds to a paraboloid $\mathrm{R}^{2}=0.65$ and will be dealt with later in Table 6 .

In all cases fits have been generated that correspond graphically to four types of possible surfaces. In Table 5 these surfaces and their corresponding equations are shown. The LF parameter is the only one that has not satisfied the $P$ value test.

The use of two architectural parameters to obtain the room acoustic parameters has given rise to many possible combinations with high values of coefficients of determination. In Table 6 the best correlations obtained for each room acoustic parameter are presented, ( $P$ value tests achieved are indicated by $\mathrm{R}^{2}$ underlined), the architectural parameters used as independent variables and the coefficients obtained in each equation are indicated. In all cases the best correlations correspond to paraboloids.

Due to the high number of satisfactory tests, the idea was born of achieving a unique pair of independent variables that give rise to good estimations of all the acoustic 
Table 5: Fitting surface types and their corresponding equations

\begin{tabular}{lc}
\hline Surface type & \multicolumn{1}{c}{ Equation } \\
Plane & $z=z_{0}+a x+b y$ \\
Paraboloid & $z=z_{0}+a x+b y+c x^{2}+d y^{2}$ \\
Gaussian & $z=\frac{z=a e^{0.5\left[\left(\frac{x-x_{0}}{b}\right)^{2}+\left(\frac{y-y_{0}}{c}\right)^{2}\right]}}{\left[1+\left(\frac{x-x_{0}}{b}\right)^{2}\right]\left[1+\left(\frac{y-y_{0}}{c}\right)^{2}\right]}$
\end{tabular}

Table 6: The most significant correlations between one acoustic parameter and a pair of geometric variables. Coefficients of paraboloids and their coefficient of determination

\begin{tabular}{|c|c|c|}
\hline Parameters & $\begin{array}{l}\text { Variables } \\
\quad(\mathbf{x}, \mathbf{y})\end{array}$ & Coefficients \\
\hline $\mathrm{T}$ & $\mathrm{S}_{\mathrm{C}}+\mathrm{S}_{\mathrm{L}}, \mathrm{V}$ & $\begin{array}{l}\mathrm{z}_{0}=-1.1800, \mathrm{a}=0.0382, \mathrm{~b}=-0.0011, \mathrm{c}=-5.6319 \cdot 10^{-5}, \mathrm{~d}=1.0483 \cdot 10^{-7} \\
\mathbf{R}^{2}=\underline{\mathbf{0 . 9 8}}\end{array}$ \\
\hline EDT & $\mathrm{S}_{\mathrm{C}}+\mathrm{S}_{\mathrm{L}}, \mathrm{V} / \mathrm{S}_{\mathrm{G}}$ & $\begin{array}{l}\mathrm{z}_{0}=9 . \overline{4507}, \mathrm{a}=0.0118, \mathrm{~b}=-1.0929, \mathrm{c}=-8.7035 \cdot 10^{-6}, \mathrm{~d}=0.0293 \\
\mathbf{R}^{\mathbf{2}}=\underline{\mathbf{0 . 9 5}}\end{array}$ \\
\hline $\mathrm{T}_{\mathrm{S}}$ & $\mathrm{S}_{\mathrm{T}}, \mathrm{V} / \mathrm{S}_{\mathrm{G}}$ & $\begin{array}{l}\mathrm{z}_{0}=737.15, \mathrm{a}=0.1206, \mathrm{~b}=-85.508, \mathrm{c}=8.3311 \cdot 10^{-6}, \mathrm{~d}=2.0725 \\
\mathbf{R}^{2}=\underline{\mathbf{0 . 9 4}}\end{array}$ \\
\hline G & $\mathrm{L}, \mathrm{H}$ & $\begin{array}{l}z_{0}=\overline{62.567}, a=-1.6906, b=-4.2273, c=0.0307, d=0.1451 \\
\mathbf{R}^{2}=\underline{\mathbf{0 . 6 5}}\end{array}$ \\
\hline $\mathrm{C}_{80}$ & $\mathrm{~V}, \mathrm{~S}_{\mathrm{T}}$ & 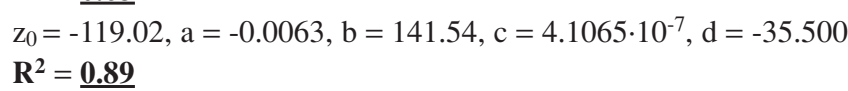 \\
\hline $\mathrm{C}_{50}$ & $\mathrm{~V}, \mathrm{~S}_{\mathrm{T}}$ & $\begin{array}{l}z_{0}=-118.41, a=-0,0064, b=137.00, c=4.0664 \cdot 10^{-7}, d=-33.740 \\
\mathbf{R}^{2}=\underline{\mathbf{0 . 8 7}}\end{array}$ \\
\hline $\mathrm{D}_{50}$ & $\mathrm{~S}_{\mathrm{C}}+\mathrm{S}_{\mathrm{L},} \mathrm{V} / \mathrm{S}_{\mathrm{T}}$ & $\begin{array}{l}z_{0}=-322.57, a=-0.5424, b=473.24, c=0.0008, d=-124.92 \\
\mathbf{R}^{2}=\underline{\mathbf{0 . 8 4}}\end{array}$ \\
\hline LF & $\mathrm{L}, \mathrm{S}_{\mathrm{C}}+\mathrm{S}_{\mathrm{L}}$ & $\begin{array}{l}z_{0}=-0.1081, a=0.0637, b=-0.0027, c=-0.0013, d=3.8939 \cdot 10^{-6} \\
\mathbf{R}^{2}=\mathbf{0 . 5 6}\end{array}$ \\
\hline RASTI & $\mathrm{S}_{\mathrm{C}}+\mathrm{S}_{\mathrm{L}}, \mathrm{V} / \mathrm{S}_{\mathrm{T}}$ & $\begin{array}{l}z_{0}=-2.0905, a=-0.0036, b=3.3722, c=5.0893 \cdot 10^{-6}, d=-0.8925 \\
\mathbf{R}^{2}=\underline{\mathbf{0 . 8 7}}\end{array}$ \\
\hline
\end{tabular}

parameters. This option again rules out the early lateral acoustic energy since it is a very difficult parameter to predict, due to being very sensitive to the position and to the nature of the different surfaces that the lateral rays encounter in each of the enclosures. Nevertheless the remaining parameters could be defined by only one pair. The best 
possibility takes the form of the tandem $(\mathrm{L}, \mathrm{H})$ that gives rise to the best regressions $(P$ value test achieved) whose calculations involves the sound distribution of the enclosure and the other parameters. The biggest drawback is that the coefficients of determination obtained using this tandem in each case are not so good, most being in the range 0.56 to 0.69 . This result does not improve on the description of the acoustic field of the churches as a function of the church height as a unique independent variable, as was discussed in Section 4.1.

If this option is adopted, the complete acoustic behaviour of the churches could be known, including the early lateral acoustic energy, by means of the three architectural parameters formed by the church length, the church mean height, and the church floor area $\left(\mathrm{L}, \mathrm{H}, \mathrm{Sc}+\mathrm{S}_{\mathrm{L}}\right)$. Anyway it seems logical that sound energy behaviour inside a closed enclosure cannot be completely explained by taking only its architectural characteristics into account and so other solutions such as those that are developed next, has been tested.

\section{ANALYSIS OF INDIVIDUAL POSITION DATA}

In the following section an analysis is carried out of the mutual correlations between the various objective acoustic parameters using the data of the individual positions in the churches. The aim is twofold: on the one hand, to seek to improve the results obtained with only geometric parameters, and on the other hand, to avoid dealing with redundant information about the room acoustic parameters. It is useful to investigate how the objective parameters themselves are interrelated, since a high correlation means that to a large extent they will be related to the design in the same way.

\subsection{Correlations between pairs of acoustic parameters}

In the following study, an analysis of the correlations obtained relating to the room acoustic parameters in pairs is carried out. Linear and polynomial correlations have been studied.

In Table 7 the most significant linear and non-linear regressions between each combination of two parameters are shown $\left(\mathrm{R}^{2}>0.5\right)$. All the correlations achieve the $P$ value test (underlined) and in all cases, (except four of them), a quadratic function $(q)$ and three linear functions (lin) in Table 7, the fits correspond to third-order polynomials, and a considerable dispersion of the experimental data exists as can be seen in Fig. 4, where, as an example, RASTI values as a function of sound strength (the poorest for RASTI variable, $\mathrm{R}^{2}=0.70$ ) are plotted. Most of the values are outside the 95\% confidence band, although the regression establishes a $95 \%$ prediction band that covers most of the measured values.

Some general features of the results should be summarized:

The early lateral acoustic energy values cannot be obtained starting from the other acoustic parameters and especially significant is the fact that the reverberation time is solely correlated with the early decay time values. The remaining parameters, including sound strength G and RASTI indices, present a high degree of correlation that equals or exceeds the value 0.7 in the coefficient of determination in all cases.

Some of the dependencies shown in Table 7 have been studied in depth, either for worship buildings $[10,17]$ or other types of enclosure [7,8]. By omitting the inclusion of all the equations in order to avoid reading unnecessary information, some significant trends that stand out from each row of regressions of Table 7 can be summarized: 
Table 7: Coefficient of determination $\left(\mathbf{R}^{2}\right)$ between pairs of acoustic parameters (third-order polynomial and the four exceptions)

\begin{tabular}{|c|c|c|c|c|c|c|c|c|c|}
\hline & $\mathbf{T}$ & EDT & $\mathbf{T}_{\mathrm{S}}$ & G & $\mathrm{C}_{80}$ & $\mathrm{C}_{50}$ & $D_{50}$ & $\mathbf{L F}$ & RASTI \\
\hline $\mathrm{T}$ & & $\underline{0.73}$ & --- & --- & --- & --- & --- & --- & --- \\
\hline EDT & & & $\underline{0.91}$ & $\underline{0.71}$ & $\underline{0.71_{\text {lin }}}$ & $\underline{0.64}$ & $\underline{0.76}$ & --- & $\underline{0.77}$ \\
\hline $\mathrm{T}_{\mathrm{S}}$ & & & & $\underline{0.79} q_{\mathrm{q}}$ & $\underline{0.96}$ & $\underline{0.82_{\text {lin }}}$ & $\underline{0.93}$ & --- & $\underline{0.86}$ \\
\hline $\mathrm{G}$ & & & & & $\overline{0.78}$ & $\overline{0.76}$ & $\overline{0.76}$ & --- & $\overline{0.70}$ \\
\hline $\mathrm{C}_{80}$ & & & & & & $\underline{0.98_{\text {lin }}}$ & $\underline{0.98}$ & --- & $\underline{0.88}$ \\
\hline $\mathrm{C}_{50}$ & & & & & & & $\underline{1}$ & --- & $\overline{0.86}$ \\
\hline $\mathrm{D}_{50}$ & & & & & & & & --- & $\underline{0.86}$ \\
\hline $\mathrm{LF}$ & & & & & & & & & $\overline{---}$ \\
\hline RASTI & & & & & & & & & \\
\hline
\end{tabular}

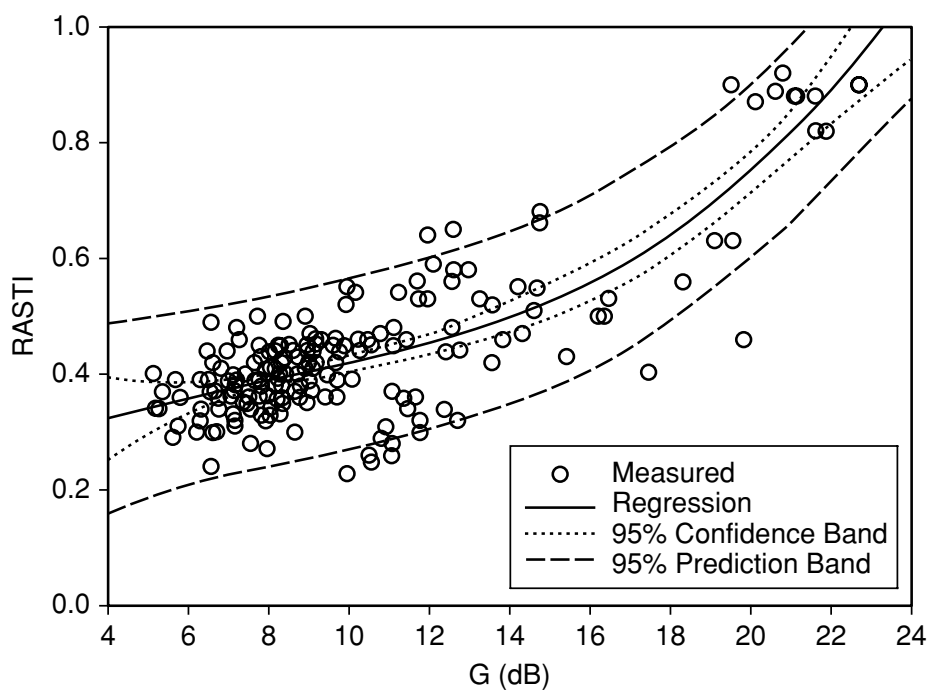

Figure 4. RASTI values as a function of $\mathrm{G}, \mathrm{R}^{2}=0.70$ as shown in Table 7 .

- EDT diminishes as either the definition, the sound strength or the RASTI values increase.

- Centre time diminishes when the clarity (or the clarity of speech or the definition) or the RASTI index increases. Otherwise it increases when the early decay time increases. Subjectively this fact implies an increase of the clarity of the enclosure when a diminution of the centre time occurs.

- $\quad$ Sound strength increases when the RASTI index increases. 
- Clarity index diminishes with the early decay time and it increases as the clarity of speech, (or the definition), or the RASTI index or the sound strength increases.

- Clarity of speech diminishes as the EDT increases, and clarity of speech increases when the definition, the sound strength or the RASTI values increase.

- Definition increases with the sound strength and the RASTI index.

The great quantity of dependencies obtained suggests that working with all the room acoustic parameters to describe the behaviour of the Mudejar-Gothic churches gives rise to an excess of information, therefore it would be appropriate to describe its acoustics with a smaller quantity. Some of these dependencies are unquestionable, for instance the ones established between the clarity for speech and definition parameters.

In order to study this hypothesis in greater depth, 3D correlations have again been tested that show this greater reciprocity between the main room acoustic parameters. The fitted surface types used correspond to those four specified in Table 5 and also fits have been analyzed which omit positions for distances smaller than the minimum distance as recommended in the ISO 3382 [2] standard so that the parameters are not affected by direct sound. It has been proved that there are no significant differences between the results.

\subsection{Correlations between three acoustic parameters}

In the same way as in the analysis of the acoustic parameters as a function of two architectural parameters, the use of two independent variables increases the number of significant correlations considerably and the coefficients of determination obtained improve substantially in most cases.

As an example, Fig. 5 presents one of the poorest three-dimensional regressions calculated: a paraboloid which corresponds to the fit of RASTI values as a function of $\mathrm{LF}$ and $\mathrm{G},\left(\mathrm{R}^{2}=0.72\right)$.

The best regressions ( $P$ value test achieved) obtained for each room acoustic parameter as dependent variables (LF excluded) correspond to paraboloids with large coefficients of determination $\left(R^{2}>0.83\right)$, except for the definition that is a Gaussian surface $\left(R^{2} \simeq 1\right)$ and whose mathematical expressions are written in eqns (12 - 19) respectively:

$$
\begin{gathered}
T=0.008+0.9056 E D T-0.0020 D_{50}-0.0117 E D T^{2}+0.0001 D_{50}{ }^{2} ; \quad R^{2}=0.84 \\
E D T=-1.9293+0.0206 T_{S}+0.0471 D_{50}-1.2113 \cdot 10^{-5} T_{S}^{2}-0.0003 D_{50}{ }^{2} ; \quad R^{2}=0.96(13) \\
T_{S}=121.6128-10.5192 C_{80}-19.8786 E D T+0.1251 C_{80}{ }^{2}+12.6286 E D T^{2} ; R^{2}=0.99(14) \\
G=15.2382-0.1198 T_{S}+5.4545 T+0.0002 T_{S}^{2}-0.8026 T^{2} ; \quad R^{2}=0.88 \\
C_{80}=4.1003-0.0262 T_{S}+0.6304 C_{50}+1.8295 \cdot 10^{-5} T_{S}{ }^{2}+0.0098 C_{50}{ }^{2} ; \quad R^{2}=0.99
\end{gathered}
$$




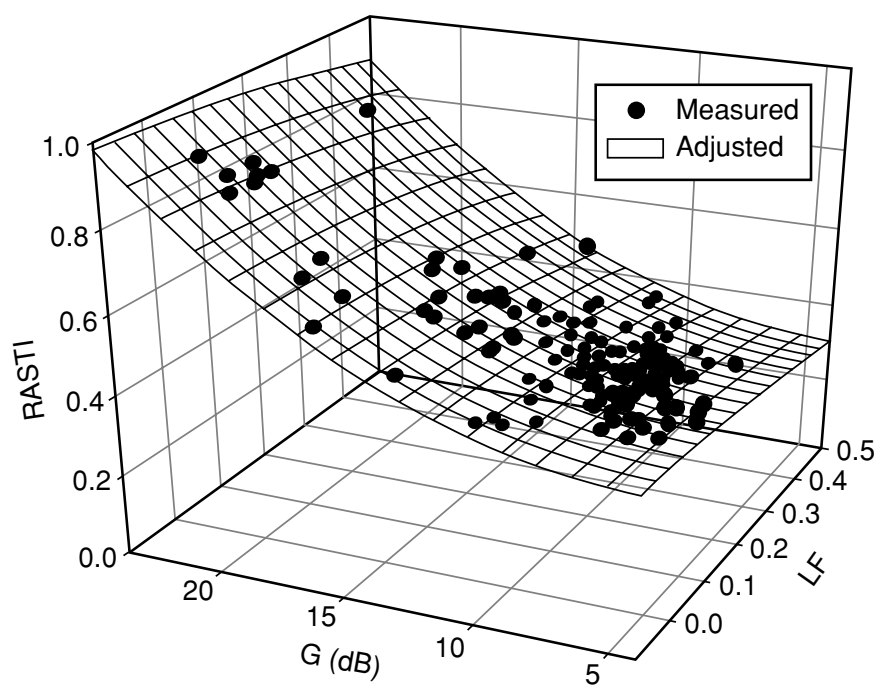

Figure 5. 3D plotted graph of RASTI as a function of G and LF acoustic parameters.

$$
\begin{gathered}
C_{50}=-6.1759+0.0353 T_{S}+1.7338 C_{80}+1.2493 \cdot 10^{-6} T_{S}{ }^{2}-0.0316 C_{80}{ }^{2} ; \quad R^{2}=0.91 \\
D_{50}=91.6024 \mathrm{e}^{-0.5\left[\left(\frac{C_{50}-10.6508}{9.6514}\right)^{2}+\left(\frac{T-2.5539}{5.9383}\right)^{2}\right]} ; \quad R^{2} \simeq 1
\end{gathered}
$$

$R A S T I=0.4083+0.0010 T_{S}+0.0238 C_{80}-3.5197 \cdot 10^{-9} T_{S}{ }^{2}+0.0016 C_{80}{ }^{2} ; R^{2}=0.89(19)$

According to all the tests carried out, the best correlation for LF corresponds to the tandem of dependant variables T, RASTI; $\left(\mathrm{R}^{2}=0.39\right)$. This is the only parameter that cannot be obtained with enough accuracy when starting from the other acoustic parameters (see Table 7), and hence its estimations are the worst.

In the studies conducted in Portuguese churches by Carvalho [10] to investigate similar correlations, it was shown that the acoustic particularities of worship places were described starting from a set of three monaural acoustic parameters. In his studies early lateral acoustic energy was not considered which in general (for concert halls and churches) appeared as an independent parameter. Four parameters would be needed therefore to characterize the inside acoustic field.

The results obtained in this case proved that only three parameters are necessary: two room acoustic parameters in order to determine the others, plus the early lateral energy fraction, LF. As it has been pointed out, Cirillo et al [17] also found the same result, working on a common typology, while Carvalho [10], who studied churches which correspond to different eras and architectural styles, needed one more independent parameter. The common typology, together with the constancy in the shape, seem to be 
Table 8: Minimum independent parameters. Results from Carvalho (C), Cirillo (Ci), Gade (G), Hidaka (H), Pelorson (P), and present work (Pr1, Pr2)*

\begin{tabular}{lcccccccc}
\hline Subjective & Objective & C & Ci & G & H & P & Pr1 & Pr2 \\
\hline Reverberance & $\mathrm{T}$ & $\dagger$ & --- & --- & $\delta$ & $\delta$ & --- & --- \\
Reverberance/Clarity & EDT, $\mathrm{T}_{\mathrm{S}}$ & --- & $\dagger$ & $\delta$ & $\delta$ & $\delta$ & $\dagger$ & $\dagger$ \\
Clarity & $\mathrm{C}_{80}$ & $\dagger$ & --- & --- & --- & -- & $\dagger$ & --- \\
Level & $\mathrm{G}$ & $\dagger$ & $\dagger$ & $\delta$ & $\delta$ & $\delta$ & --- & --- \\
Spatial Impression & LF, IACC & NA & $\dagger$ & $\delta$ & $\delta$ & $\delta$ & $\dagger$ & $\dagger$ \\
Speech Intelligibility & RASTI, $_{50}, \mathrm{D}_{50}$ & --- & --- & $\mathrm{NA}$ & $\mathrm{NA}$ & $\delta$ & --- & $\dagger$ \\
\hline
\end{tabular}

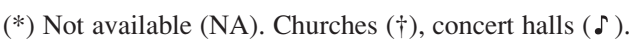

decisive factors in the reduction of the number of descriptor parameters of the acoustics in these enclosures. Furthermore, in the Mudejar-Gothic churches, the range of geometric values (church width, height and length) presents a great uniformity, a fact that seems to propitiate the dependencies obtained.

In addition, several combinations of pairs of parameters exist which allow the acoustic behaviour to be described, especially those formed by the tandem $\left(\mathrm{T}_{\mathrm{S}}, \mathrm{C}_{80}\right)$ or (EDT, $\mathrm{D}_{50}$ ). In most cases, the correlations correspond to paraboloid surfaces with a coefficient of determination $\mathrm{R}^{2} \geq 0.80$ in all cases. Specific correlations that correspond to Lorentzian and Gaussian surfaces exist.

The two tandems presented show great similarity since the first and second member of each pair are highly correlated to each other (see Table $7, \mathrm{~T}_{\mathrm{S}}$ with EDT, and $\mathrm{C}_{80}$ with $D_{50}$ ). In each pair its first member takes the clarity of the enclosure into account subjectively, while its second member, which corresponds to early-to-late or early-tototal energy ratios, carries information about the musical clarity or about the definition of speech. In any case the pairs of independent variables that serve from base to determine the remaining acoustic parameters (bearing in mind the exclusion of LF), correspond to parameters which are very sensitive to position.

Another discussion of the results is conducted through a comparison of the independent acoustic descriptors found in this paper with those in pieces of work of the same nature carried out in concert halls and churches. This comparison is shown in Table 8 where the association of each subjective attribute of sound perception with the corresponding objective parameter has been deduced from Barron's [24] study for music and the widely accepted criteria for speech intelligibility.

Although a strict comparison is not possible due to the variety and omissions of parameters measured in the separate studies certain features may be highlighted: All results indicate that spatial impression is an independent attribute. Furthermore, having taken all 6 attributes into account by means of the measured parameters, the number of independent acoustic variables (3) in the present work on Mudejar-Gothic churches coincides with that of Cirillo's work on Apulian-Romanesque churches consisting of 
buildings of the same typology. Nevertheless, in the present study (in both 3-parameter proposals) level never appeared as an independent variable in spite of being one in all the other analyses in churches and concert halls.

Finally, it should be pointed out that the study of mixed correlations which uses one geometric parameter and one room acoustic parameter as independent variables has been omitted. Although it is certain that good correlations would be achieved, the inclusion of one room acoustic parameter supposes that the in situ impulse response must be obtained, for which no improvement could be supposed regarding the use of two room acoustic parameters as independent variables. Meanwhile, correlations which involve reverberation time, volume and source-receiver positions are possible in each church, in fact an analytical model based on these variables and on measured clarity results is able to predict definition, clarity for speech, centre time and sound strength ${ }^{19}$ and rapid speech transmission inde $\mathrm{x}^{20}$ values as a function of source-receiver distances; the spatial distribution of lateral energy fraction ${ }^{21}$ values has also been discussed from the point of view of this analytical model in these temples.

\section{CONCLUSIONS}

This paper studies the statistical correlations found between monaural acoustic parameters with geometrical variables and with acoustic parameters themselves in a survey of 12 Mudejar-Gothic churches in the city of Seville in southern Spain.

Measurements were taken between the $125-4000 \mathrm{~Hz}$ octave band in multiple locations in each church, and both linear and non-linear regression have been used in the analysis. The acoustic parameters were spectrally averaged according to the most widely accepted way in order to qualify room acoustic quality and the correlations have been tested between the spatially averaged values in the room (each church is characterized by a single value) and with the full set of positional data.

The best correlations between position-averaged parameters and the geometric parameters correspond to non-linear functions, where the geometric values are used as independent variables (one or two variables). The functions correspond to third-order polynomials. It has been impossible to establish a minimum group of architectural parameters to describe all room acoustic parameters because none of the architectural characteristics studied is related to the early lateral acoustic energy. The architectural parameter resulting in the best fits is constituted by the $\mathrm{V} / \mathrm{S}_{\mathrm{T}}$ ratio of the churches which gives a first indication of the trends of the acoustic parameters, except for the early lateral acoustic energy, as mentioned earlier. The correlations increase in number when two geometric parameters are used as independent variables and with much better results for the coefficient of determination. To describe the complete list of subjective acoustic attributes in these churches, three architectural parameters are necessary, consisting of the height, the width and the ground floor area, this last parameter involving the floor area of the central nave and lateral naves. However, in this case, the coefficients of determination are in the range between 0.56 and 0.69 , and $P<0.05$.

This procedure was repeated by analyzing correlations exclusively between the room acoustic parameters. According to the statistical analysis ( $P$ value), the acoustic parameters proved to be more robust variables than the architectural variables. The 
relationships which involve pairs of parameters with third-degree polynomials, indicated the great dependence between them in almost all cases and has led to their study with two independent variables. These results also show the need for a set of three acoustic parameters to describe the acoustic behaviour of the churches studied, although in this case with a much higher coefficient of determination in the correlations than the one obtained in the tests with architectural parameters as independent variables. When taking the early lateral acoustic energy into consideration, the best cases correspond to the pair formed by the centre time and the clarity, or the early decay time and the definition. In concert halls, the number of parameters suggested for measurement when the 6 subjective attributes of sound are taken into account, are four or more (see Table 8) which are bound together with the perception of reverberation, sound distribution, clarity and spaciousness. An exception to this is Gade's study where the number of essential parameters is also three but no single parameter related to speech intelligibility was included in the analysis (neither $\mathrm{C}_{50}$, nor $\mathrm{D}_{50}$ nor RASTI). In the churches included in Carvalho's analysis on different style Portuguese churches, the spatial impression, which is always assumed as an independent parameter, increases the number of essential parameters for the evaluation of the 6 subjective attributes of sound to four (Table 8). Nevertheless, the conclusions drawn here for the Mudejar-Gothic churches are in accordance with those reached by Cirillo et al who also pointed out that only three parameters were essential to describe the acoustic field of Apulian-Romanesque churches. One possible explanation for this reduction in the number of independent variables is the common typology, the constancy in the forms and the small variation in the ranges of the geometric parameters. These features are thus associated to this reduction to the three subjective aspects in the Mudejar-Gothic church case: reverberance/clarity, clarity or speech intelligibility, and spatial impression.

\section{ACKNOWLEDGEMENTS}

The authors would like to express their gratitude to the priests and church management for allowing the measurements to be carried out. This work has been partially supported by the Spanish MCYT project BIA2003-09306-CO4-02.

\section{REFERENCES}

[1] ISO 18233 Acoustics-Application of new measurement methods in building and room acoustics 2006.

[2] ISO 3382. Acoustics-Measurement of the reverberation time of rooms with reference to other acoustical parameters 1997.

[3] ISO/DIS 3382-1. Acoustics-Measurement of room acoustic parameters. Part 1: Performance rooms.

[4] Schroeder, M. R., Gottlob, D., Siebrasse, K. F., Comparative study of European concert halls: correlation of subjective preference with geometric and acoustic parameters, Journal of the Acoustical Society of America, 1974, 56 (4), 1195-1201.

[5] Gade, A. C., Acoustical survey of eleven European concert halls- a basis for discussion of halls in Denmark, The acoustical laboratory, Technical university of Denmark, report 44. ISBN: 0 105-3027, 1989. 
[6] Gade, A. C., The influence of architectural design on the acoustics of concert halls, Applied Acoustics, 1990, 31(1-3), 207-214.

[7] Pelorson, X. Vian, J.P., Polack, J.D., On the variability of room acoustical parameters: reproducibility and statistical validity, Applied Acoustics 1992, 37 (3), $175-198$.

[8] Hidaka, T., Nishihara, N., Objective evaluation of chamber-music halls in Europe and Japan, Journal of the Acoustical Society of America, 2004, 116 (1), 357-372.

[9] Carvalho, A. P., Objective Acoustical Analysis of Room Acoustic Measurements in Portuguese Roman Catholic Churches, Proceedings of the NOISE-CON 94, Fort Lauderdale, FL (E.U.A.), May 1994.

[10] Carvalho, A. P., Relationships between Objective Acoustical Measurements and Architectural Features in Churches, Sabine Centennial Symposium/127th ASA Meeting, Cambridge, MA (E.U.A.), June 1994.

[11] Carvalho, A. P., Speech Intelligibility in Churches. How it relates with Objective Acoustical Parameters and Architectural Features, 133rd Meeting of the Acoustical Society of America, PennState (E.U.A.), June 1997.

[12] Carvalho, A. P., Relations between Rapid Speech Transmission Index (RASTI) and other Acoustical and Architectural Measures in Churches, Applied Acoustics, 1999, 58 (1), 33-49.

[13] Carvalho, A. P., Relationships between subjective and objective acoustical measures in churches, Journal of Building Acoustics, 1997, 4 (1), 1-20.

[14] Magrini, A., Ricciardi, P., An Experimental Study of Acoustical Parameters in Churches, International Journal of Acoustics and Vibration, 2002, 7 (3), 177-183.

[15] Magrini, A., Ricciardi, P., Churches as Auditoria: Analysis of acoustical Parameters for a Better Understanding of Sound Quality, Journal of Building Acoustics, 2003, 10 (2), 135-158.

[16] Cirillo, E., Martellota, F., Acoustics of Apulian-Romanesque churches: an experimental survey, Journal of Building Acoustics, 2002, 9(4), 271-288.

[17] Cirillo, E., Martellota, F., Acoustics of Apulian-Romanesque churches: Correlations Between Architectural and Acoustic Parameters, Journal of Building Acoustics, 2003, 10 (1), 55-76.

[18] Galindo, M., Zamarreño, T., Girón, S., Acoustic analysis in Mudejar-Gothic churches: Experimental results, Journal of the Acoustical Society of America, 2005, 117 (5), 2873-2888.

[19] Zamarreño, T., Girón, S., Galindo, M., Acoustic energy relations in MudejarGothic churches, Journal of the Acoustical Society of America, 2007, 121 (1), 234-250.

[20] Zamarreño, T., Girón, S., Galindo, M., Assessing the intelligibility of speech and singing in Mudejar-Gothic churches, Applied Acoustics, 2008, 69 (3), 242-254. 
[21] Girón, S., Galindo, M., Zamarreño, T., Distribution of lateral acoustic energy in Mudejar-Gothic churches, Journal of Sound and Vibration, 2008, 315, 1125-1142.

[22] IEC 60268-16. Sound system equipment, Part 16: Objective rating of speech intelligibility by speech transmission index. International Electrotechnical Commission. Geneva, Switzerland, 2003.

[23] Marshall, G. L., An acoustic measurement program for evaluating auditoriums based on the early/late sound energy ratio, Journal of the Acoustical Society of America, 1994, 96, 2251-2261.

[24] Barron, M. Subjective study of British symphony concert halls, Acustica, 1988, 66(1), 1-14. 